\title{
Compilation of a panel of informative single nucleotide polymorphisms for bovine identification in the Northern Irish cattle population
}

\author{
Adrian R Allen 1*, Malcolm Taylor ${ }^{1}$, Brian McKeown², April I Curry ${ }^{1}$, John F Lavery', Andy Mitchell²,
} David Hartshorne ${ }^{2}$, Rüdi Fries ${ }^{3}$, Robin A Skuce ${ }^{1}$

\begin{abstract}
Background: Animal identification is pivotal in governmental agricultural policy, enabling the management of subsidy payments, movement of livestock, test scheduling and control of disease. Advances in bovine genomics have made it possible to utilise inherent genetic variability to uniquely identify individual animals by DNA profiling, much as has been achieved with humans over the past 20 years. A DNA profiling test based on bi-allelic single nucleotide polymorphism (SNP) markers would offer considerable advantages over current short tandem repeat (STR) based industry standard tests, in that it would be easier to analyse and interpret. In this study, a panel of 51 genome-wide SNPs were genotyped across panels of semen DNA from 6 common breeds for the purposes of ascertaining allelic frequency. For SNPs on the same chromosome, the extent of linkage disequilbrium was determined from genotype data by Expectation Maximization (EM) algorithm. Minimum probabilities of unique identification were determined for each breed panel. The usefulness of this SNP panel was ascertained by comparison to the current bovine STR Stockmarks II assay. A statistically representative random sampling of bovine animals from across Northern Ireland was assembled for the purposes of determining the population allele frequency for these STR loci and subsequently, the minimal probability of unique identification they conferred in sampled bovine animals from Northern Ireland.
\end{abstract}

Results: 6 SNPs exhibiting a minor allele frequency of less than 0.2 in more than 3 of the breed panels were excluded. 2 Further SNPs were found to reside in coding areas of the cattle genome and were excluded from the final panel. The remaining 43 SNPs exhibited genotype frequencies which were in Hardy Weinberg Equilibrium. SNPs on the same chromosome were observed to have no significant linkage disequilibrium/allelic association. Minimal probabilities of uniquely identifying individual animals from each of the breeds were obtained and were observed to be superior to those conferred by the industry standard STR assay.

Conclusions: The 43 SNPs characterised herein may constitute a starting point for the development of a SNP based DNA identification test for European cattle.

\section{Background}

Animal \& Food Traceability - Conventional Approaches and Problems

The identification and registration of livestock and monitoring of their movements is an essential part of

\footnotetext{
* Correspondence: adrian.allen@afbini.gov.uk
'Agri-Food and Biosciences Institute, Stoney Road, Belfast, Northern Ireland

* Correspondence: adrian.allen@afbini.gov.uk
${ }^{1}$ Agri-Food and Biosciences Institute, Stoney Road, Belfast, Northern Ireland, BT4 3SD, UK
} BT4 350, UK

agricultural policy for national governments. Such schemes underpin disease control, grant and subsidy management, food hygiene/safety assurance and facilitate product recalls if necessary.

As a result of these benefits, and also in response to major animal health problems such as BSE (Bovine Spongiform Encephalopathy) and Foot and Mouth Disease that impact livestock, producers and consumers, many countries in the developed world have adopted 
national databases, based on numbered ear tags, to record cattle identity and movements [1,2].

Trade globalisation has also strengthened the case for improved animal traceability. Modern consumers confronted with increased choice from multiple sources may also face elevated risks as a result of increased likelihood of chemical/pathogenic contamination in foodstuffs $[3,4]$. Such crises can compromise the economic well being of agri-food industries as well as affecting the health and confidence of the consumer. The BSE crisis of the 1990s aptly demonstrates both points and proves that the actions of one state can impact negatively on the public health of others [5].

In light of the potential dangers highlighted above, the European Union (EU) passed Council Directive 92/102/ EEC stating that all bovine animals in Member States should be identified with an ear-tag bearing a unique identification code [6]. The more far reaching Council Regulations 1760/2000 and article 18 of regulation 178/ $2002[7,8]$, established the need for Member States to control registration and tracking of bovine animals through a computerised database based on a two ear-tag system. These enhanced traceability regulations also extended to the products derived from the animal after slaughter, insisting that batches of meat must be able to be tracked back to animal's of origin by use of carcase, primal and pack labelling. These regulations were designed to ensure that full animal and meat traceability was "established at all stages of production, processing and distribution".

Future development of tag schemes may include the use of electronic identification devices such as radio frequency identification (RFID) ear-tags, ruminal boluses and injectable transponders which automate the reading of animal identity, thereby reducing transcription errors [9].

Whilst lauding the ability of such systems to improve farm management, a recent EU report on uses of electronic identification in the agri-food industries (the IDEA project - IDentification Electronique des Animaux - http://idea.jrc.it/) confirmed that the preferred option, RFID ear-tags, still suffered from the same accidental tag loss and fraudulent switching problems which afflict conventional schemes [10].

Animal mis-identification resulting from tag loss has profound epidemiological and traceability implications which can result in costly consequences for herd keepers. The extent of tag loss and its negative impact on the ability to re-assign correct ID has been highlighted in a recent study in intensively farmed buffalo, which revealed mean conventional ear-tag retention time to be 272 days [11]. Similarly, deficiencies in meat labelling at abattoirs and at retail outlets have resulted in loss of correct association between batch numbers and samples.
A recent study used DNA traceability to indicate that $2 \%$ of randomly selected samples from labelled carcases at the abattoir did not match the profiles of the animals they were purported to come from. This increased to $3 \%$ when sampling was conducted at the point of sale [12].

The root of these problems in conventional and electronic tagging/labelling systems arises from their reliance on methods which track devices attached to animals and their products, but not the animals or products themselves. However, DNA profiling, which utilises unalterable biological properties of individual animals to produce a unique identifier, offers a potential solution for scientifically verifying animal identity [13]. At present the technology does not exist for DNA profiles to be read in 'real time', unlike tags and labels. This limits DNA's use as a primary identifier of animals and derived food products. However, despite these limitations it can be used effectively in retrospective audits to verify tag identity and quality assure existing meat tracing technologies $[1,3,14,15]$. The added advantage of DNA based parentage verification makes it a powerful method for verifying national herd database information.

\section{DNA markers and DNA Profiling}

The level of polymorphic variation observed in bovine short tandem repeats (STRs) permits the use of relatively few loci to identify cattle and to determine their parentage $[16,17]$. Several well defined cattle STR panels are commercially available. One such 11 marker panel has been approved by the International Society of Animal Genetics (ISAG) for use by breed societies to register pedigree sires and dams and their progeny.

Single Nucleotide polymorphisms (SNPs) are a much simpler form of DNA variation than microsatellites, involving a single nucleotide change at one position of the genetic code. This lack of diversity makes SNP markers less informative than microsatellites. As a result, single SNPs don't discriminate between individuals very well. However, genotyping of multiple SNPs can overcome this problem [18].

SNP genotyping also has distinct advantages over STR genotyping. Owing to their smaller size, they are less prone to gametic mutation and therefore do not suffer from the same non-identical by descent problems that can affect STRs as they mutate between generations [18]. SNPs are also more robust in their interpretation/ analysis than STRs [19] and can be genotyped by a variety of high throughput methods on various platforms, many of which can be automated with economy of scale savings [20]. With the advent of ever-improving genotyping technologies [21], it has recently become attractive to develop a SNP-based DNA profiling system for the identification of cattle. Two SNP panels have recently been assembled for this purpose $[18,22]$. 


\section{Cattle Farming in Northern Ireland}

There are approximately 1.7 million cattle in Northern Ireland spread over 25000 herds with an average herd size of seventy animals. The Department of Agriculture and Rural Development (DARD) runs a computer database called the Animal and Public Health Information System (APHIS) based on the two ear tag system required by the European Commission $[7,8]$. This system manages identification, registration, movement, testing, subsidy payment and general traceability of animals. To date, APHIS facilitates the registration of all animal births, movements, test histories and slaughter [1].

\section{Study Aims}

We attempted to assemble a panel of SNPs which would identify animals from the Northern Irish population. SNP panels previously identified by Heaton et al., 2002 and Werner et al., 2004 [18,22] were characterised in our cattle population to determine which would uniquely identify bovine animals. An allele frequency study was carried out in representative breed panels of the most common breeds used in Northern Ireland. This work was undertaken using a semen archive of sires from each of the six predominant cattle breeds, unrelated at the parent and grandparent level.

For validation purposes, it was desirable to compare the capability of any new SNP panel against the existing industry standard test. We STR genotyped a representative subset of the Northern Irish Cattle population using the ISAG approved Stockmarks II system. A general random sampling across the whole province that included many breeds was considered sufficient to determine allele frequencies for each locus and subsequently to help determine the minimum probability of finding two animals that possessed the same STR profile. Ultimately this would enable us to ascertain the uniqueness of STR profiles in our population, vital information for deployment of this technology as a counter fraud and traceability tool.

\section{Results}

Allele frequencies of the 51 SNPs genotyped across the semen DNA panels from six breeds are listed in the Additional file 1 Table S1). Six SNPs which exhibited minor allele frequency less than $20 \%$ in more than three of the breed panels were excluded (16_2, 448_67, 487_67, Bulge101, MBS047-1 and 454_G11).

Allele frequencies of the remaining 45 SNPs were used to calculate expected genotype frequencies in each of the breed panels. Chi squared analysis of expected and observed genotype frequencies revealed no significant difference $(p>0.05)$ for any of the SNPs. This indicates that in each of the breed panels, all SNPs are in Hardy Weinberg Equilibrium (HWE) (Additional file 1 Table S1).
Exact chromosomal locations including contig accession numbers for each of the 45 remaining SNPs on the current build of the bovine genome were determined by the NCBI's BLAST (Basic Local Alignment Search Tool) (Table 1). Two further SNPs were excluded because they encoded amino acids in proteins and were not deemed to be selectively neutral (MBS030-1 and MBS031-1) (Table 1).

Several of the remaining 43 SNPs were observed to exist on the same chromosome. Genotype data for SNPs located on the same chromosomes were collated from each of the six breeds studied, and subjected to EM algorithm analysis to determine the degree of allelic association/linkage disequilbirum (LD) between polymorphisms (Table 1).

The frequencies of the most common 43 SNP genotypes from each of the six breeds were then collated to determine the minimal probability of uniquely identifying unrelated animals from each breed. These probabilities ranged over three orders of magnitude from $2.45 \times$ $10^{-11}$ to $4.65 \times 10^{-13}$ (Table 2 ).

Allele frequencies of the eleven STRs tested in the representative sampling of the Northern Irish cattle population are listed in Additional file 2 Table S2. Expected genotype frequencies were calculated from allele frequency data and compared by Chi squared analysis against observed genotype frequencies. This result revealed no significant difference $(p>0.05)$ between observed and expected genotypes (Additional file 2 Table S2) indicating that each locus is in HWE. The minimal probability of uniquely identifying an individual animal using the STR markers was determined to be $1.89 \times 10^{-9}$ (Table 2).

\section{Discussion}

In selecting a panel of SNPs which would uniquely identify Northern Irish animals we were presented with several novel problems. Initially, which SNPs should be selected? Some of the best characterised SNPs at the inception of this work were those described by Werner et al. and Heaton et al., [18,22]. However unlike the Stockmarks STR based system, these SNPs were not well characterised across a variety of cattle breeds from different countries. The Northern Irish cattle population, whilst possessing many of the same breeds as those seen in Europe and the USA, may have been subject to region-specific population changes and inbreeding which could result in SNP allele frequencies slightly different than those observed in other countries. Therefore, it is plausible that a panel that is useful in one population may not necessarily be as useful in another [19]. As a result, it was essential to perform an allele frequency study for each SNP in our population to ensure that non-informative SNPs (minor allele frequency less than 
Table 1 SNP id, chromosome and contig locations including Linkage Disequilibrium between SNP pairs on the same chromosome. D' was calculated by EM algorithm between pairs of SNPs in adjacent order

\begin{tabular}{|c|c|c|c|c|c|c|}
\hline $\begin{array}{l}\text { SNP } \\
\text { Name }\end{array}$ & Chromosome & $\begin{array}{l}\text { Contig Accession } \\
\text { no. }\end{array}$ & $\begin{array}{l}\text { Base position in } \\
\text { Contig }\end{array}$ & $\begin{array}{l}\text { Genbank } \\
\text { SNP id }\end{array}$ & $\begin{array}{l}\text { Is SNP coding or non } \\
\text { coding? }\end{array}$ & $\begin{array}{l}\text { Combined Breeds Linkage } \\
\text { Disequilibrium }\left(D^{\prime}\right)\end{array}$ \\
\hline 027.sp6 & 1 & $\begin{array}{l}\text { [Genbank: } \\
\text { NW_001493890] }\end{array}$ & 3818758 & SS_182258874 & Non coding intronic & 027.sp6 - 421_10 D'=0.18 \\
\hline$\overline{421 \_10}$ & 1 & $\begin{array}{l}\text { [Genbank: } \\
\text { NW_001493804] }\end{array}$ & 583808 & SS_182258864 & Non coding intronic & \\
\hline MBS029-1 & 2 & $\begin{array}{l}\text { [Genbank: } \\
\text { NW_001494698] }\end{array}$ & 3047667 & rs17871918 & Non Coding & MBS029-1 - MBS042-1 D'=0.02 \\
\hline MBS042-1 & 2 & $\begin{array}{l}\text { [Genbank: } \\
\text { NW_001494591] }\end{array}$ & 108095 & rs41257512 & Non coding intronic & \\
\hline $018 . s p 6$ & 3 & $\begin{array}{l}\text { [Genbank: } \\
\text { NW_001494745] }\end{array}$ & 2606666 & SS_182258872 & Non coding intronic & 018.SP6 - 486_67 D' $=0.41$ \\
\hline $486 \_67$ & 3 & $\begin{array}{l}\text { [Genbank: } \\
\text { NW_001494789] }\end{array}$ & 1283668 & SS_182258886 & Non Coding & \\
\hline 417_16 & 4 & $\begin{array}{l}\text { [Genbank: } \\
\text { NW_001494939] }\end{array}$ & 1975758 & SS_182258885 & Non Coding & 417_16-MBS048-1 D'=0.12 \\
\hline MBS048-1 & 4 & $\begin{array}{l}\text { [Genbank: } \\
\text { NW_001494921] }\end{array}$ & 1019822 & rs17871345 & Non coding intronic & \\
\hline$\overline{431 \_A 2}$ & 5 & $\begin{array}{l}\text { [Genbank: } \\
\text { NW_001495040] }\end{array}$ & 1991472 & SS_182258884 & Non Coding & $\begin{array}{l}\text { Exclude SNP MBS030-1 } \\
\text { MBS007-1 - 431_A2 D'=0.09 }\end{array}$ \\
\hline MBS007-1 & 5 & $\begin{array}{l}\text { [Genbank: } \\
\text { NW_001495013] }\end{array}$ & 223977 & rs41256853 & Non coding intronic & $\begin{array}{l}\text { MBS007-1 - MBS043-1 } D^{\prime}=0.06 \\
431 \_A 2-M B S 043-1 D^{\prime}=0.12\end{array}$ \\
\hline MBS030-1 & 5 & $\begin{array}{l}\text { [Genbank: } \\
\text { NW_001494990] }\end{array}$ & 1339300 & rs17871971 & $\begin{array}{l}\text { Coding - first base in } \mathrm{R} \\
\text { codon }\end{array}$ & \\
\hline MBS043-1 & 5 & $\begin{array}{l}\text { [Genbank: } \\
\text { NW_001495111] }\end{array}$ & 1628598 & rs29003967 & Non coding intronic & \\
\hline $013 . s p 6$ & 6 & $\begin{array}{l}\text { [Genbank: } \\
\text { NW_001495169] }\end{array}$ & 651244 & Ss_182258871 & Non coding intronic & $013.5 p 6-A H 2-5 D^{\prime}=0.20$ \\
\hline $\mathrm{AH} 2-5$ & 6 & $\begin{array}{l}\text { [Genbank: } \\
\text { NW_001495205] }\end{array}$ & 919203 & rs41255759 & Non coding intronic & \\
\hline MBS044-1 & 7 & $\begin{array}{l}\text { [Genbank: } \\
\text { NW_001495330] }\end{array}$ & 1925089 & rs17870555 & Non coding intronic & N/A \\
\hline $128 . s p 6$ & 8 & $\begin{array}{l}\text { [Genbank: } \\
\text { NW_001495453] }\end{array}$ & 6360496 & Ss_182258880 & Non coding intronic & N/A \\
\hline 004.sp6 & 9 & $\begin{array}{l}\text { [Genbank: } \\
\text { NW_001495578] }\end{array}$ & 257732 & SS_182258869 & Non coding & $\begin{array}{l}423 \_24-425 \_2 D^{\prime}=0.48 \\
423 \_24-004.5 p 6 D^{\prime}=0.10\end{array}$ \\
\hline 423_24 & 9 & $\begin{array}{l}\text { [Genbank: } \\
\text { NW_001495569] }\end{array}$ & 793596 & SS_182258865 & Non Coding & 425_2 - 004.sp6 $D^{\prime}=0.04$ \\
\hline $425 \_2$ & 9 & $\begin{array}{l}\text { [Genbank: } \\
\text { NW_001495569] }\end{array}$ & 839251 & SS_182258866 & Non coding intronic & \\
\hline $022 . t 7$ & 10 & $\begin{array}{l}\text { [Genbank: } \\
\text { NW_001492799] }\end{array}$ & 128540 & SS_182258873 & Non coding intronic & Exclude SNP MBS031-1 \\
\hline MBS031-1 & 10 & $\begin{array}{l}\text { [Genbank: } \\
\text { NW_001492799] }\end{array}$ & 1124499 & rs17871372 & $\begin{array}{l}\text { Coding - third base in } \\
\text { C codon }\end{array}$ & \\
\hline $055 . t 7$ & 11 & $\begin{array}{l}\text { [Genbank: } \\
\text { NW_001492961] }\end{array}$ & 1632290 & SS_182258877 & Non coding & $\begin{array}{l}\text { AH8-4 - 055.t7 D' = } 0.02 \\
\text { AH8-4 - MBS015-1 D' = } 0.21\end{array}$ \\
\hline $\mathrm{AH} 8-4$ & 11 & $\begin{array}{l}\text { [Genbank: } \\
\text { NW_001492942] }\end{array}$ & 738417 & rs41255717 & Non coding intronic & $055 . t 7-\mathrm{MBS} 015-1 \mathrm{D}^{\prime}=0.09$ \\
\hline MBS015-1 & 11 & $\begin{array}{l}\text { [Genbank: } \\
\text { NW_001493001] }\end{array}$ & 1324153 & rs17871661 & Non coding intronic & \\
\hline 058.sp6 & 12 & $\begin{array}{l}\text { [Genbank: } \\
\text { NW_001493063] }\end{array}$ & 1152348 & SS_182258883 & Non coding & N/A \\
\hline $\mathrm{AH} 25-1$ & 13 & $\begin{array}{l}\text { [Genbank: } \\
\text { NW_001493148] }\end{array}$ & 1355813 & rs41257524 & Non Coding & $\mathrm{AH} 25-1-\mathrm{MBS} 046-1 \mathrm{D}^{\prime}=0.20$ \\
\hline MBS046-1 & 13 & $\begin{array}{l}\text { [Genbank: } \\
\text { NW_001493168] }\end{array}$ & 1973152 & rs41257490 & Non coding intronic & \\
\hline
\end{tabular}


Table 1: SNP id, chromosome and contig locations including Linkage Disequilibrium between SNP pairs on the same chromosome. D' was calculated by EM algorithm between pairs of SNPs in adjacent order (Continued)

\begin{tabular}{|c|c|c|c|c|c|c|}
\hline 436_C10 & 14 & $\begin{array}{l}\text { [Genbank: } \\
\text { NW_001493182] }\end{array}$ & 723654 & SS_182258882 & Non Coding & $\mathrm{N} / \mathrm{A}$ \\
\hline Bulge105 & 16 & $\begin{array}{l}\text { [Genbank: } \\
\text { NW_001493378] }\end{array}$ & 486637 & SS_182258868 & Non coding intronic & N/A \\
\hline MBS018-1 & 17 & $\begin{array}{l}\text { [Genbank: } \\
\text { NW_001493523] }\end{array}$ & 2800849 & rs41255724 & Non coding intronic & $\mathrm{N} / \mathrm{A}$ \\
\hline 105.sp6 & 18 & $\begin{array}{l}\text { [Genbank: } \\
\text { NW_001493559] }\end{array}$ & 10050072 & SS_182258881 & Non coding & $\begin{array}{l}\text { 105.sp6 - MBS033-1 } D^{\prime}=0.07 \\
105 . s p 6-M B S 021-1 \quad D^{\prime}=0.41\end{array}$ \\
\hline MBS021-1 & 18 & $\begin{array}{l}\text { [Genbank: } \\
\text { NW_001493612] }\end{array}$ & 23880 & rs17871403 & Non Coding & MBS033-1 - MBS021-1 D'=0.07 \\
\hline MBS033-1 & 18 & $\begin{array}{l}\text { [Genbank: } \\
\text { NW_001493607] }\end{array}$ & 941203 & rs17871744 & Non coding intronic & \\
\hline 039.t7 & 19 & $\begin{array}{l}\text { [Genbank: } \\
\text { NW_001493666] }\end{array}$ & 1151813 & SS_182258875 & Non coding & $039 . t 7-M B S 054-1 D^{\prime}=0.11$ \\
\hline MBS054-1 & 19 & $\begin{array}{l}\text { [Genbank: } \\
\text { NW_001493688] }\end{array}$ & 831437 & rs41257458 & Non coding intronic & \\
\hline 007.sp6 & 20 & $\begin{array}{l}\text { [Genbank: } \\
\text { NW_001493983] }\end{array}$ & 863397 & SS_182258870 & Non coding intronic & Bulge113 - 007.sp6 D' = 0.18 \\
\hline Bulge 113 & 20 & $\begin{array}{l}\text { [Genbank: } \\
\text { NW_001493954] }\end{array}$ & 1202924 & SS_182258867 & Non Coding & \\
\hline 048.sp6 & 21 & $\begin{array}{l}\text { [Genbank: } \\
\text { NW_001494027] }\end{array}$ & 363121 & SS_182258876 & Non coding intronic & $\mathrm{N} / \mathrm{A}$ \\
\hline MBS025-1 & 23 & $\begin{array}{l}\text { [Genbank: } \\
\text { NW_001494145] }\end{array}$ & 446755 & rs41255852 & Non coding intronic & MBS025-1 - MBS035-1 D'=0.05 \\
\hline MBS035-1 & 23 & $\begin{array}{l}\text { [Genbank: } \\
\text { NW_001494172] }\end{array}$ & 276736 & rs17872223 & Non coding intronic & \\
\hline MBS028-1 & 24 & $\begin{array}{l}\text { [Genbank: } \\
\text { NW_001494262] }\end{array}$ & 534627 & rs17870274 & Non coding intronic & N/A \\
\hline 070.t7 & 25 & $\begin{array}{l}\text { [Genbank: } \\
\text { NW_001494320] }\end{array}$ & 325234 & SS_182258878 & Non coding & MBS040-1 - 070.t7 D'=0.05 \\
\hline MBS040-1 & 25 & $\begin{array}{l}\text { [Genbank: } \\
\text { NW_001494295] }\end{array}$ & 390532 & rs17872131 & Non coding intronic & \\
\hline 090.t7 & 28 & $\begin{array}{l}\text { [Genbank: } \\
\text { NW_001501727] }\end{array}$ & 3153055 & SS_182258879 & Non coding & N/A \\
\hline MBS041-1 & 29 & $\begin{array}{l}\text { [Genbank: } \\
\text { NW_001494538] }\end{array}$ & 322380 & rs17870855 & Non coding intronic & N/A \\
\hline
\end{tabular}

$20 \%)$ were not used in the final panel. Within populations of cattle there will also be differences in observed allele frequencies between breeds, just as is seen in subgroups of different race/ethnicity in the human population. Indeed recent work by the Bovine HapMap consortium has illustrated the great diversity that exists between breeds and the conversely small diversity within breeds. This is indicative that the taurine ancestors of all modern Bos taurus breeds were very genetically diverse post-domestication, and that subsequent founder effects at time of breed formation and resulting small effective population size caused reduced diversity within breeds [23]. Therefore, we endeavoured to determine allele frequencies of the candidate SNPs in six of the most commonly seen breeds in Northern Ireland. Only 6 of the 51 SNPs studied were observed to exhibit minor allele frequencies of lower than $20 \%$ in three or more of the six breeds studied. This indicates that the vast majority of the panel described herein is suitable for use in identifying cattle of the major breeds found in Northern Ireland.

The fact that all SNPs were in HWE is indicative that random genetic drift and selection have not acted on these loci, or on loci in linkage disequilibrium with them and that they are subsequently stable markers, which can be used as identifiers.

SNPs used for identification purposes should ideally come from non-coding parts of the bovine genome since these regions are less likely to be influenced by natural or artificial selection, which could alter their allelic frequency over a period of time. SNPs affected by selection would not be sufficiently stable between generations to act as identifiers. MBS030-1 and MBS031-1 were excluded from the final SNP panel because they 
Table 2 Minimal probabilities of unique identity conferred by the 43 SNP panel and 11 STR assay.

\begin{tabular}{lll}
\hline Marker Type & Study Population & Probability of Identity \\
\hline 11 STR assay & NI representative sampling & $1.89 \times 10^{-9}$ \\
\hline 43 SNP assay & A. Angus semen archive & $2.45 \times 10^{-11}$ \\
\hline 43 SNP assay & Belgian Blue semen archive & $3.31 \times 10^{-12}$ \\
\hline 43 SNP assay & Charolais semen archive & $6.17 \times 10^{-12}$ \\
\hline 43 SNP assay & Holstein semen archive & $4.65 \times 10^{-13}$ \\
\hline 43 SNP assay & Limousin semen archive & $1.96 \times 10^{-12}$ \\
\hline 43 SNP assay & Simmental semen archive & $2.36 \times 10^{-12}$ \\
\hline
\end{tabular}

reside in coding regions of the bovine genome. Whilst HWE is observed for these SNPs in all tested breeds, indicating that selection is not playing a role, it was decided to exclude them since it was feasible that at some stage in the future a selective event could conceivably affect allele frequency.

Finally, to further maximise the discriminatory power of each individual SNP it was necessary to ensure that those occurring on the same linkage unit/chromosome, did not exhibit strong allelic association/linkage disequilibrium in this population. Allelic association between SNPs would render one of a pair completely uninformative as an identifier. Whilst Werner et al and Heaton et al had positioned their respective panels on chromosomes using fluorescence in situ hybridisation and linkage mapping respectively, only Heaton et al [22] had calculated the LD between SNPs on the same chromosomes. Quantification of LD between SNPs from both of these panels had not been undertaken. LD in the bovine genome has been observed to extend over large distances $(1 \mathrm{Mb})$ with an average haplotype block size of between 26 and $113 \mathrm{~kb}$ [24]. This extent of LD over large distances exceeds that observed in humans and is caused by reduced allelic diversity resulting from small effective population sizes as a consequence of breed formation bottlenecks $[23,24]$. The latter also highlights the fact that spacing of potential identification markers very far apart is necessary to ensure maximum discriminatory power. In this study, we benefitted from the recent completion of the bovine genome and were able to exactly place the SNPs studied onto contigs of the sequenced bovine chromosomes by use of BLAST sequence alignment software on the NCBI website. LD calculation by EM algorithm indicated that for all SNPs sharing chromosomes, the values of D' were low. Subsequent Haploview analysis of these $D^{\prime}$ values and their confidence bounds revealed that they lie outside the default D' confidence interval (upper bound 0.98; lower bound 0.70) defined by Gabriel et al. as constituting a tightly bound block of high allelic association [25]. These data are indicative that the alleles of SNPs residing on the same chromosomes can segregate independently of one another, thereby retaining their informativity as unique identifiers.

The probabilities of the unique 43 SNP-based identity determined for each of the breeds in this study are comparable to those described by Werner et al and Heaton et al for a comparable number of SNPs. In reality, within pedigree and non pedigree herds, there is a greater reliance on breeding with the same sires and dams, and consequently a higher level of relatedness between animals. This reduces the allelic diversity greatly within such herds and subsequently increases the probability that two individual animals sired in different matings of the same sire/dam pair can possess the same SNP derived DNA profile. Consequently, it may require the genotyping of a few additional SNPs in such related animals to uniquely identify them. The bovine HapMap Consortium's data on a genome wide survey of SNP variation across several cattle breeds [23] takes account of the degree of relatedness between animals of the same breed, and indicates that approximately 50 SNPs should be used to determine the identity of animals and uniquely identify them with a match probability of $1.3 \times 10^{-15}$.

In comparison to the commercially available ISAG approved set of STR markers, the potential discriminatory power of this SNP panel is significantly greater. Providing a suitable platform can be found to run the SNPs described in multiplex, the benefits of a next generation SNP-based DNA profiling system are substantial. Running costs could be reduced and analysis made simpler. Inter-laboratory comparisons and standardisation would be easier to achieve as a result of the bi-allelic simplicity of SNPs compared to more polymorphic STRs. Future test panels could also incorporate the

Table 3 Breed breakdown of random Northern Ireland cattle population sampling.

\begin{tabular}{ll}
\hline Cattle Breed & No. \\
\hline Aberdeen Angus* & 34 \\
\hline Belgian Blue* & 33 \\
\hline Blonde D'Acquitaine & 16 \\
\hline Charolais* & 73 \\
\hline Dexter & 3 \\
\hline Hereford & 11 \\
\hline Holstein* & 28 \\
\hline Jersey & 1 \\
\hline Limousin* & 112 \\
\hline Parthenaise & 1 \\
\hline Salers & 4 \\
\hline Shorthorn & 8 \\
\hline Simmental* & 42 \\
\hline Total: & 366 \\
\hline
\end{tabular}

* Breeds used in SNP allele frequency study. 
growing number of SNP markers associated with desirable phenotypes/quantitative traits.

In Northern Ireland, cattle DNA profiling has been evaluated in several scenarios assure the existing tag based method of identification. These include the auditing of meat plants involved in processing over thirty month animals for TSE (Transmissible Spongiform Encephalopathy) surveillance, quality assurance of removal of tuberculosis and brucellosis infected animals from affected herds and investigations into alleged fraudulent identity swapping. The technique has also been deployed to aid farmers in re-establishing the identity of animals which have lost ear-tags and subsequently fall foul of animal identification requirements. In future, it is conceivable that DNA profiling could be used as a means of auditing the entire APHIS system in a way which is more powerful than any paper based audit. It is also foreseeable that such a traceability system could expand to become an effective means of tracking animals and their products from 'gate to plate'. These developments would greatly enhance the traceability capability of the existing system and lead to greater consumer and producer confidence.

\section{Conclusions}

In recent times, international consortia have been moving towards configuration of a high throughput SNP based assay for cattle identification and parentage verification purposes. We believe that whilst more SNPs could be added to increase the discriminatory power between closely related individuals, the panel characterised here serves as a good starting point for many of the major European cattle breeds.

\section{Methods}

\section{Sample sets}

Semen samples were collected for the six major cattle breeds used in Northern Ireland - Limousin $(n=37)$, Belgian Blue $(n=35)$, Simmental $(n=32)$, Charolais $(n$ $=34)$, Aberdeen Angus $(n=38)$ and Holstein $(n=29)$. Pedigree information was used to ensure that genotyped animals from each breed panel were unrelated at the parent and grandparent levels.

From statutory annual testing of all females and breeding bulls over twelve months of age in the national herd, a randomly selected sub-sample of clotted blood from 366 animals from across Northern Ireland's ten Divisional Veterinary Offices (DVO) were selected for inclusion in a population representative sample set collected over a 6 month period. This sample set provided a confidence level of $95.0 \%$ that allelic frequencies observed were representative of the greater national bovine population. Numbers of animals per breed are shown in Table 3.

\section{DNA Extraction}

DNA was extracted from both clotted blood and semen samples using Qiagen QIAamp DNA Mini kits (Cat no. 51306) following manufacturers instructions.

\section{PCR and analysis}

\section{SNP}

DNA derived from semen (50 ng) was subjected to single-plex PCR for each of the SNPs genotyped. $20 \%$ of samples were genotyped a second time for quality control. PCR reactions were carried out in $25 \mu \mathrm{l}$ total volume, $2 \mathrm{mM} \mathrm{MgCl}_{2}, 0.2 \mu \mathrm{M}$ of each primer, $2 \mathrm{mM}$ of each dNTP, $10 \mathrm{mM}$ Tris- $\mathrm{HCl}, 50 \mathrm{mM} \mathrm{KCl}, 0.5 \mathrm{U}$ of Qiagen HotStar Taq polymerase. The cycling conditions used were an initial $96^{\circ} \mathrm{C}$ for 15 minutes to activate the hot start Taq, followed by 35 cycles of $30 \mathrm{~s}$ denaturation at $96^{\circ} \mathrm{C}, 1 \mathrm{~min} 30 \mathrm{~s}$ annealing at $53^{\circ} \mathrm{C}$ and $1 \mathrm{~min} 30 \mathrm{~s}$ extension at $72^{\circ} \mathrm{C}$. Amplification products were SNP genotyped by pyrosequencing [26]. Genbank accession numbers of sequences containing all SNPs and location of SNPs are available [18,22].

\section{STR}

DNA derived from clotted blood (50 ng) was subjected to multiplex PCR at the eleven microsatellite markers in the Applied Biosystem's Bovine Stockmarks II assay (Cat no. 4307480) as suggested by the manufacturer. Amplified products were resolved by gel capillary electrophoresis on an Applied Biosystems ABI3100 Genetic Analyser. Analysis and allele calling was performed using Applied Biosystems Gene-Mapper software.

\section{Statistics}

The NCBI bovine genome BLAST tool was utilised to determine the exact physical location of each of the SNP markers in the recent draft of the bovine genome, Btau 4. Using Haploview [27], EM algorithm was then applied to SNP genotype data to determine the level of linkage disequilibrium (D') observed between markers on the same chromosome. Subsequent comparison of observed D' confidence bounds to a default D' confidence interval, defined as being indicative of significant allelic association by Gabriel et al [25], was undertaken using Haploview [27]. This permitted determination of whether pairs of SNP alleles analysed displayed significant levels of linkage disequilibrium/allelic association, or were able to segregate independently.

Allele frequency data was used to determine population genotype frequencies for both sets of markers. Chi squared analysis of expected and observed genotype frequencies was undertaken to ensure that alleles observed were in HWE. Most common genotype frequencies at each marker were then determined. These most common genotype frequencies were then multiplied together and used to determine the minimal probability of two randomly drawn animals from the same population possessing the same SNP or STR profile [14]. 
Additional file 1: SNP allele frequency data. All SNP allele frequency data for each of the six breeds studied are contained in this table along with Hardy Weinberg chi square $p$ values, most common genotypes and most common genotype frequency.

Click here for file

[http://www.biomedcentral.com/content/supplementary/1471-2156-11-5S1.DOC ]

Additional file 2: STR allele frequency data. All STR allele frequency data for the $\mathrm{NI}$ cattle population representative random sampling are contained in this table along with Hardy Weinberg chi square $p$ values, most common genotypes and most common genotype frequency. Click here for file

[http://www.biomedcentral.com/content/supplementary/1471-2156-11-5S2.DOC ]

\section{Acknowledgements}

Thanks to Dr Stanley McDowell of AFBI Stormont for his advice on population representative random sampling. Sincere thanks to Mr Brian Kennedy of Al Services who provided sire semen straws for all breeds genotyped. Thanks also to Dr Krzysztof Flisikowski (Technical University of Munich) Dr Mike Heaton and Dr Ted Kalbfleisch (USDA) for help with identifying SNP markers. This project was funded by The Department of Agriculture and Rural Development for Northern Ireland, under its Vision for the future of the Agri-Food Industry' research programme.

\section{Author details}

${ }^{1}$ Agri-Food and Biosciences Institute, Stoney Road, Belfast, Northern Ireland, BT4 3SD, UK. ${ }^{2}$ Orchid Cellmark, 16 Blacklands Way, Abingdon Business Park, Abingdon, Oxfordshire, OX14 1DY, UK. ${ }^{3}$ Lehrstuhl fuer Tierzucht, der Technischen Universitaet Muenchen, Alte Akademie 12, D-85354 FreisingWeihenstephan, Deutschland/Germany.

\section{Authors' contributions}

AA designed and performed SNP genotyping assays, participated in the study design determined allele frequencies, performed statistical analysis and drafted the manuscript. MT participated in study design and genotyping of STR markers. BMcK participated in study design and contributed to SNP genotyping. AC designed and performed SNP genotyping assays, contributed to databasing of results and oversaw extraction of DNA from blood and semen samples. JL performed STR genotyping and databasing of results and oversaw extraction of DNA from blood and semen samples. $\mathrm{AM}$ and DH contributed to study design. RF contributed to study design and provided SNP sequence details. RS conceived of the study and contributed to study design. All authors have read and approved the final manuscript.

Received: 2 July 2009

Accepted: 25 January 2010 Published: 25 January 2010

\section{References}

1. Houston R: A computerised database system for bovine traceability. Revue Scientifique et Technique 2001, 20:652-661.

2. Buick W: Animal Passports and Identification. Defra Veterinary Journal 2004, 15:20-26.

3. Caporale V, Giovannini A, Di Francesco C, Calistri P: Importance of the traceability of animal products in epidemiology. Revue Scientifique et Technique 2001, 20:372-378.

4. McKean JD: The importance of traceability for public health and consumer protection. Revue Scientifique et Technique 2001, 20:363-371.

5. McGrann J, Wiseman H: Animal traceability across national frontiers in the European Union. Revue Scientifique et Technique 2001, 20:406-412.

6. Ammendrup S, Fussel AE: Legislative requirements for the identification and traceability of farm animals within the European Union. Revue Scientifique et Technique 2001, 20:437-444.

7. Commission of the European Communities 2000, Regulation (EC) No. 1760/ 2000 of the European Parliament and of the Council of 17 July 2000: Establishing a system for the identification and registration of bovine animals and regarding the labelling of beef and beef products and repealing Council Regulation (EC) No. 820/97. Off J Eur Communities L 204:1-10.

8. Council Regulation (EC) No 178/2002 of the European Parliament and of the Council of 28 January 2002: Laying down the general principles and requirements of food law, establishing the European Food Safety Authority and laying down procedures in matters of food safety. Off $J$ Eur Communities L 31:1-24.

9. Ribo O, Korn C, Meloni U, Cropper M, De Winne P, Cuypers M: IDEA: a large scale project on electronic identification of livestock. Revue Scientifique et Technique 2001, 20:426-436.

10. Report From The Commission To The Council And The European Parliament: On the possibility of introduction of electronic identification for bovine animals. 2005http://eur-lex.europa.eu/LexUriServ/LexUriServ.do? uri=COM:2005:0009:FIN:EN:PDF.

11. Fosgate GT, Adesiyun AA, Hird DW: Ear-tag retention and identification methods for extensively managed water buffalo (Bubalus bubalis) in Trinidad. Preventive Veterinary Medicine 2006, 73:287-296.

12. Capoferri R, Bongioni G, Galli A, Aleandri R: Genetic Control of Conventional Labelling through the Bovine Meat Production Chain by Single Nucleotide Polymorphisms Using Real Time PCR. Journal of Food Protection 2006, 69:1971-1977.

13. Pettitt RG: Traceability in the food animal industry and supermarket chains. Revue Scientifique et Technique 2001, 20:584-597.

14. Cunningham EP, Meghen CM: Biological Identification Systems: genetic markers. Revue Scientifique et Technique 2001, 20:491-499.

15. Raspor P: Bio-markers: traceability in food safety issues. Acta Biochimica Polonica 2004, 52:659-664.

16. Glowatzki-Mullis ML, Gaillard C, Wigger G, Fries R: Micorsatellite based parentage control in cattle. Animal Genetics 1995, 26:7-12.

17. Heyen DW, Beever JE, Da Y, Evert RE, Green C, Bates SR, Ziegle JS, Lewin HA: Exclusion probabilities of 22 bovine microsatellite markers in fluorescent multiplexes for semi automated parentage testing. Animal Genetics 1997, 28:21-27.

18. Werner FAO, Durstewitz G, Habermann FA, Thaller G, Kramer W, Kollers $S$, Buitkamp J, Georges M, Brem G, Mosner J, Fries R: Detection and characterization of SNPs useful for identity control and parentage testing in major European dairy breeds. Animal Genetics 2004, 35:44-49.

19. Krawczak M: Informativity assessment for bi-allelic single nucleotide polymorphisms. Electrophoresis 1999, 20:1676-1681.

20. Kruglyak $L$ : The use of a genetic map of biallelic markers in linakage studies. Nature Genetics 1997, 17:21-24.

21. Kim S, Misra A: SNP genotyping: technologies and biomedical applications. Annual Review of Biomedical Engineering 2007, 9:289-320.

22. Heaton MP, Harhay GP, Bennett GL, Stone RT, Grosse WM, Casas E, Keele JW, Smith TPL, Chitkon-McKown CG, Laegreid WW: Selection and use of SNP markers for animal identification and paternity analysis in U.S. beef cattle. Mammalian Genome 2002, 13:272-281.

23. HapMap Consortium: Genome Wide Survey of SNP Variation Uncovers the Genetic Structure of Cattle Breeds. Science 2009, 324:528-532.

24. Kim ES, Kirkpatrick BW: Linkage Disequilibrium in the North American Holstein population. Animal Genetics 2009, 40:279-288.

25. Gabriel SB, Schaffner SF, Nguyen H, Moore JM, Roy J, Blumenstiel B, Adeyemo A, Cooper R, Ward R, Lander ES, Daly MJ, Altshuler D: The structure of haplotype blocks in the human genome. Science 2002, 296:2225-2229.

26. Ronaghi $M$, Uhlen $M$, Nyren $P$ : A sequencing method based on real time pyro-phosphate. Science 1998, 281:363-365.

27. Barrett JC, Fry B, Maller J, Daly MJ: Haploview: analysis and visualization of LD and haplotype maps. Bioinformatics 2005, 21(2):263-265.

doi:10.1186/1471-2156-11-5

Cite this article as: Allen et al:: Compilation of a panel of informative single nucleotide polymorphisms for bovine identification in the Northern Irish cattle population. BMC Genetics 2010 11:5. 